\title{
From outlier to trendsetter
}

$\mathrm{T}$ he world's brand-name drug makers have long viewed India as their problem child for delaying compliance with international property rights law while serving as the developing world's pharmacy for generic drugs.

Although India eventually agreed to comply with the World Trade Organization's Agreement on Trade Related Aspects of Intellectual Property Rights (TRIPs), it made it clear that it fully intended to use a provision of international law that allows for the so-called "compulsory licensing" of generic drugs that are the therapeutic equivalents of their patented counterparts in the interests of ensuring the poor and disadvantaged have access to drugs (www.cmaj.ca/lookup/doi/10.1503/cmaj .109-3898).

That day has come as India has issued its first patent compulsory licensing order, for the kidney/liver cancer drug sorafenib, and started a deep ripple in the global pharmaceutical pond. China, the target market of many brand-name drug makers, quickly amended its intellectual property law to allow for the compulsory licensing of generic drugs "for reasons of public health." Argentina and the Philippines have indicated they'll soon do the same, while in other nations, such as Malaysia, local groups are pressing the government to grant a compulsory licence to a second-line antiretroviral used in the treatment of HIV/AIDS.

India's first post-TRIPs compulsory licence, issued in March, allowed NATCO Pharma Limited to produce a generic version of sorafenib, the patent for which is held by German drug giant Bayer AG, on the grounds that the brand-name version was not "reasonably affordable." The licence entitles
NATCO to sell the drug at about $3 \%$ of Bayer's price. That substantially reduces the cost of a monthly, 120tablet dose of the drug to 8880 rupees (roughly \$180) from 280428 rupees (about \$5500) (http://pib.nic.in/newsite /erelease.aspx? relid=82984). The license requires NATCO to pay Bayer a royalty of " $6 \%$ of the net sales of the drug" and to supply the drug free of cost to at least 600 "needy and deserving" patients annually.

There's no question that the licence was justified on public health grounds, argues Dr. Kunal Saha, president of the nongovernmental advocacy group People for Better Treatment. "In a country like India, where a large fraction of the population is still in the lower rungs of the economic ladder with very little money to spend on health care, there can be nothing wrong with the fundamental reason for the

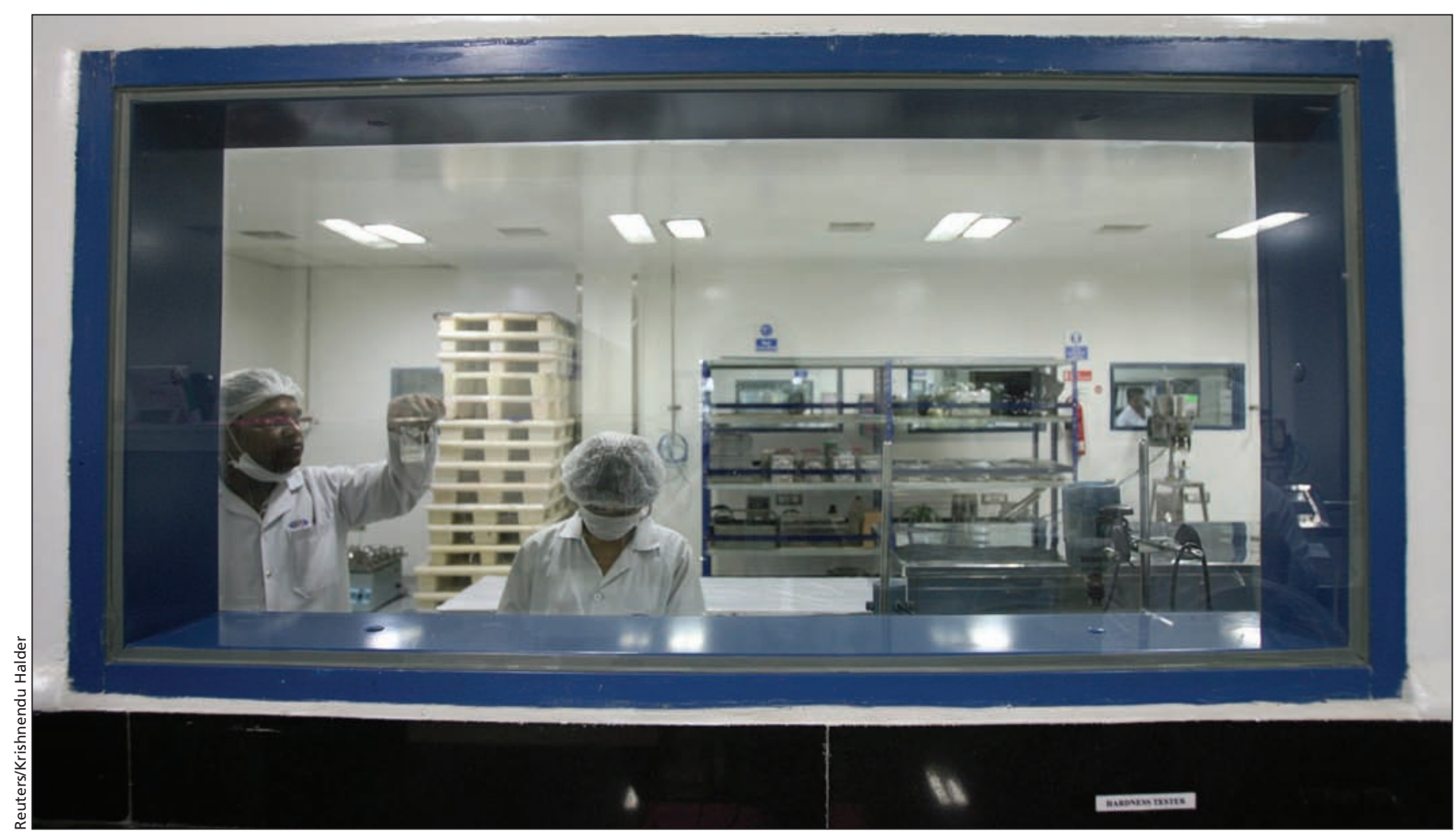

Pharmacologists work inside Natco Research Centre in the southern Indian city of Hyderabad. While issuing its first compulsory license, India stripped German drug maker Bayer of its exclusive rights to a cancer drug and allowed generic maker Natco Pharma to make and sell a cheap version. 
compulsory licence order issued recently by the Indian patent office because, in simple terms, it will reduce the price of many drugs that have been monopolized by few selective and wealthy drug companies," says Saha.

Compulsory licensing will increasingly be a necessity for many nations, argues Dr. P. Khadgapathi, chairman of the industrial pharmaceutical division of the Indian Pharmaceutical Association. The association "supports the move of compulsory licensing and feels that it is a must for not only developing and underdeveloped nations but also developed nations," he says. "The decision of compulsory licensing is based on the health needs of a nation and various other factors, like availability, affordability of drugs, etc. Previously, other nations, like USA too, have adopted similar moves during the anthrax scare."

Brand-name drug makers counter that compulsory licensing makes it difficult for them to invest millions of dollars in researching and developing new drugs. Bayer has already appealed the compulsory licensing order with the Intellectual Property Appellate Board in a bid to defend "intellectual property rights which are a prerequisite for bringing innovative medicines to patients," Mandira Viegas, a spokesman for the Bayer Group in India writes in an email. "The order of the Patent Con- troller of India damages the international patent system and endangers pharmaceutical research. The limited period of marketing exclusivity made possible by patents ensures that the costs associated with the research and development of innovative medicines can be recovered."

But some analysts say that this argument is based on a faulty premise. "For years, advocates questioning the high prices of new drugs have heard the familiar threat from the drug manufacturers that reducing prices will mean less money for research," says Musa Mayer, a patient advocate in the US and a consultant with the US Food and Drug Administration's Cancer Drug Development Program. "I believe the picture is far more complex than that, and that this is merely a tactic."

The government of India, meanwhile, has indicated that its long-term plans include greater use of compulsory licences. "In consultation with concerned Ministries, local production of bulk drugs and vaccines should be encouraged to build 'drug security' in the country. The MoHFW [Ministry of Health \& Family Welfare] should identify and get compulsory license issued for patented expensive drugs required for public health programmes, and encourage their manufacture in the country," the government's Health Division Planning
Commission states in the Report of the Steering Committee on Health for the 12th Five-Year Plan (http://planning commission.nic.in/aboutus/committee /strgrp12/str_health0203.pdf).

Somewhat surprisingly, compulsory licensing also appears to have had an effect on the price of other cancer drugs. The Indian pharmaceutical giant Cipla Ltd., for example, announced that it was slashing the price of three anticancer drugs by $59 \%-75 \%$ (www.cipla .com/whatsnew/news.htm\#03may12).

Mayer is hopeful that the long-term consequences for consumers will be lower prices but frets that patients in developed countries will have to pay higher prices to offset reduced industry profits in the developing world.

"Clearly this kind of inequity in pricing cannot continue indefinitely," she notes. "The whole house of cards that is drug pricing worldwide could be threatened by what is occurring in India and elsewhere. That might be a good thing. Perhaps the free-market economists should put their money where their mouths are and actually let the market work and see what the real value of these cancer drugs actually is to patients - what is known as 'value pricing'. I think we would all be shocked." Soumyadeep Bhaumik MBBS and Tamoghna Biswas, Kolkata, India

CMAJ 2012. DOI:10.1503/cmaj.109-4246 